\title{
Final Height of Japanese Patients with X-Linked Hypophosphatemic Rickets: Effect of Vitamin D and Phosphate Therapy
}

\author{
Junko MIYAMOTO*, Shinobu KOTO* AND Yukihiro HASEGAWA*,** \\ * Endocrinology, Metabolism and Genetics Unit, Tokyo Metropolitan Kiyose Children's Hospital, Tokyo, 204-8756 Japan \\ ** Pharmacia-Upjohn Fund for Growth and Development Research, Keio University School of Medicine, Tokyo 160-0016 Japan
}

\begin{abstract}
X-linked hypophosphatemic rickets (XLH) is one of the most common causes of rickets in infancy and childhood. Combination therapy of vitamin D and phosphate is generally used for patients with XLH. Effect of treatment of vitamin D and phosphate during childhood on final height of XLH has to be elucidated in Japanese. There have been only three Caucasian studies on final height of XLH with treatment since childhood. Purpose of this study is to report adult height and therapeutic effect of 22 Japanese participants (5 males, 17 females) with XLH who were treated with phosphate (33-200 $\mathrm{mg} / \mathrm{kg} /$ day as phosphorus divided into 3 or 4 doses) and vitamin D (vitamin $\mathrm{D}_{2}$ or $1 \alpha$-hydroxyvitamin $\mathrm{D}_{3}$ ) for more than five years and evaluate effect of the treatment on the final height retrospectively. Final height $(\mathrm{FHt})$ for all participants was $-1.69 \pm 1.11 \mathrm{SD}$. FHt $(-1.69 \pm 1.11 \mathrm{SD})$ was significantly higher than height at the initiation of treatment $(-2.38 \pm 0.88 \mathrm{SD})$ for all participants $(\mathrm{P}<0.01)$. In conclusion, combination therapy of vitamin D and phosphate improved final height of Japanese patients with XLH as is similar to previous Caucasian studies.
\end{abstract}

Key words: XLH, Japanese, Final height, Vitamin D, Phosphate

(Endocrine Journal 47: 163-167, 2000)

X-LINKED hypophosphatemic rickets (XLH) is one of the most common causes of rickets in infancy and childhood. Mutations in the PHEX gene (phosphate regulating gene with homologies to endopeptidases on the X-chromosome) are thought to be responsible for XLH. Pathogenic mechanism of XLH involves two defects, impaired proximal tubular reabsorption of phosphate and abnormal regulation of 1,25-dihydroxyvitamin D metabolism. XLH during childhood is characterized clinically by rachitic skeletal deformities and growth retardation. Combination therapy of vitamin $\mathrm{D}$ and phosphate is generally used

Received: August 18, 1999

Accepted: January 19, 2000

Correspondence to: Yukihiro HASEGAWA, M.D., Endocrinology, Metabolism and Genetics Unit, Tokyo Metropolitan Kiyose Children's Hospital, 1-3-1 Umezono, Kiyose, Tokyo 204-8756, Japan for patients with $\mathrm{XLH}$, and it is reported that the combination of vitamin $\mathrm{D}$ and phosphate improved the mineralization of trabecular bone [1-6].

Effect of treatment of vitamin D and phosphate on adult height in Japanese population for XLH has yet to be determined. There are five reports of final height [1-5]. Yoshikawa et al. reported only two patients [4]. Berndt et al. and Reusz et al. were from the same group [5, 6]. All reports on final height except for Yoshikawa et al. were from Caucasian studies.

The purpose of this study is to report final height and therapeutic effect of 22 Japanese participants with XLH who were treated with phosphate and vitamin $\mathrm{D}$ for more than five years and evaluate effect of treatment on the final height retrospectively. 


\section{Methods}

\section{Participants}

Twenty-two Japanese (5 males, 17 females) were the participants (backgrounds of 21 participants of 22 were previously reported [7]). They were diagnosed as having XLH in our clinic between 1966 and 1989. Diagnosis was made based on the findings of hypophosphatemia (serum inorganic phosphorus; $1.5-3.0 \mathrm{mg} / \mathrm{dl})$, renal phosphate wasting (TmP/ GFR $<3 \mathrm{mg} / 100 \mathrm{mlGFR}$ ), normocalcemia (serum calcium level; $8.7-10.8 \mathrm{mg} / \mathrm{dl}$ ), elevated alkaline phosphatase level (above the age-matched normal values), absence of aminoaciduria and hypercalciuria (urine calcium/creatinine; $0.00-0.21$ ), and radiological evidence of rickets.

They were treated with phosphate $(33-200 \mathrm{mg} /$ $\mathrm{kg} /$ day as phosphorus divided into 3 or 4 doses) and vitamin $\mathrm{D}$ (vitamin $\mathrm{D}_{2}$ or $1 \alpha$-hydroxyvitamin $\mathrm{D}_{3}$ ) orally until completion of growth (Table 1). Therapeutic dose of vitamin D and phosphate was adjusted to maintain serum inorganic phosphorus concentration in the normal range 1 to 2 hours after per oral use of phosphate while avoiding hypercalcemia (serum calcium level over $10.3 \mathrm{mg} / \mathrm{dl}$ ) and hypercalciuria (urine calcium/creatinine over 0.3). Initial dosages of phosphate and vitamin $\mathrm{D}$ were shown in Table 1. Three of 22 participants had undergone osteotomies. Two of the three were treated with vitamin $\mathrm{D}_{2}$ and one of the three were treated with $1 \alpha$-hydroxyvitamin $\mathrm{D}_{3}$.

The participants were subdivided into two groups on the basis of a type of vitamin D treatment. Group $D_{2}$ included 10 participants who were treated with vitamin $\mathrm{D}_{2}$. Group $\alpha \mathrm{D}_{3}$ included 12 participants who were treated with $1 \alpha$-hydroxyvitamin $\mathrm{D}_{3}$. All 22 participants were treated with phosphate. There was no significant difference in age at initiation of treatment (Group $\mathrm{D}_{2} ; 54.7 \pm 50.3$ months, Group $\alpha \mathrm{D}_{3} ; 47.0 \pm 42.7$ months), duration of the combination therapy (Group $\mathrm{D}_{2} ; 11.2 \pm 3.3$ years, Group $\alpha \mathrm{D}_{3} ; 12.0 \pm 2.3$ years) or ratio of male and female between group $\mathrm{D}_{2}$ and group $\alpha \mathrm{D}_{3}$ (Table 1).

\section{Analysis of growth}

Measurements of height and laboratory tests were performed two or three times every year. Height was evaluated as standard deviation score (SDS) at each age [8]. The following three growth data were used in evaluation of height: Final height (FHt), Target height (THt), and Height at the initiation of treatment (IHt). FHt was defined as height when height velocity was less than $1 \mathrm{~cm} /$ year. Target height was defined as (height of mother theight of father \pm 13) $/ 2$ ( + for male and - for female [9]). Three participants whose mothers were proved to be patients with XLH were evaluated only by FHt and IHt. Three participants who had undergone osteotomies were included; their height velocities did not change after osteotomies compared with the height velocities before the osteotomies (data not shown).

Improvement of height was retrospectively evaluated by the following three parameters: FHt, difference between FHt and IHt $(=\mathrm{FHt}-\mathrm{IHt})$, and difference between FHt and THt ( $=$ FHt-THt).

The following factors that could have influence on growth were analyzed retrospectively: gender; IHt; age at the initiation of treatment; inorganic phosphorus level at the initiation of treatment; initial

Table 1. Characteristics of the study population

\begin{tabular}{ccc}
\hline & Group $\mathrm{D}_{2}$ & Group $\alpha \mathrm{D}_{3}$ \\
\hline $\mathrm{n}$ & 10 & 12 \\
Gender (male/female) & $3 / 7$ & $2 / 10$ \\
Age (years old) & $30.3 \pm 5.8$ & $24.1 \pm 5.0$ \\
Family history of rickets & $\mathrm{n}=1$ & $\mathrm{n}=2$ \\
Age at the initiation of treatment & $54.7 \pm 50.3($ month) & $47 \pm 42.7$ (month) \\
Height at the initiation of treatment & $-2.73 \pm 0.78(\mathrm{SD})$ & $-2.07 \pm 0.88(\mathrm{SD})$ \\
Dosage at the initiation of treatment & & \\
(1) vitamin D & $5400 \pm 2700(\mathrm{U} / \mathrm{kg})$ & $0.11 \pm 0.04(\mu \mathrm{g} / \mathrm{kg})$ \\
(2) phosphate & $92.5 \pm 47.0(\mathrm{mg} / \mathrm{kg} / \mathrm{day})$ & $142 \pm 48.0(\mathrm{mg} / \mathrm{kg} / \mathrm{day})$ \\
\hline
\end{tabular}


dosage of vitamin D treatment; initial dosage of phosphate treatment.

\section{Statistical analysis}

To compare Group $\mathrm{D}_{2}$ and $\alpha \mathrm{D}_{3}$ as for FHt and IHt, and male and female, Mann-Whitney's U test was used. Correlation between improvement of height and either IHt, age at the initiation of treatment, inorganic phosphorus level at the initiation of treatment, initial dosage of vitamin $\mathrm{D}$, or initial dosage of phosphate were analyzed with simple regression and stepwise regression. Probability values of less than 0.05 were considered as significant. Descriptive values are shown as mean \pm SD in this manuscript.

\section{Results (Table 2)}

\section{(1) Improvement of height}

Two growth charts, one for responders (1A), and the other for non-responders (1B), are shown in Fig. 1. Height became higher since initiation of treatment with vitamin $\mathrm{D}$ and phosphate, especially in Fig. 1A.

FHt was $-2.07 \pm 0.84$ SD for group $D_{2}$ and $-1.38 \pm 1.24$ SD for group $\alpha \mathrm{D}_{3}$. There was no significant difference between the two groups. FHt for all participants was $-1.69 \pm 1.11 \mathrm{SD}$.

FHt was significantly higher than IHt for each group. FHt $(-2.07 \pm 0.84 \mathrm{SD})$ was significantly higher than IHt $\left(-2.73 \pm 0.78\right.$ SD) for group $\mathrm{D}_{2}$ $(\mathrm{P}<0.01)$. FHt $(-1.38 \pm 1.24 \mathrm{SD})$ was significantly higher than IHt $(-2.07 \pm 0.88)$ for group $\alpha \mathrm{D}_{3}$ $(\mathrm{P}<0.01)$. FHt $(-1.69 \pm 1.11 \mathrm{SD})$ was significantly higher than IHt $(-2.38 \pm 0.88 \mathrm{SD})$ for all participants.

FHt-THt was $-1.41 \pm 1.21$ SD for group $\mathrm{D}_{2}$ and
$-1.19 \pm 1.14$ SD for group $\alpha \mathrm{D}_{3}$. There was no significant difference between the two groups. FHtTHt for all participants was $-1.31 \pm 1.10 \mathrm{SD}$.

\section{(2) Factors that could have an influence on improve- ment of height}

There was no significant difference of $\mathrm{FHt}$ between male $(-1.73 \pm 1.10 \mathrm{SD})$ and female $(-1.68 \pm 1.14$ $\mathrm{SD})$.

Simple regression showed two factors significantly correlated with FHt: IHt SDS $(r=0.70, p=0.0008)$, and Age at the initiation of treatment $(r=-0.56$, $\mathrm{p}=0.0063$ ). The other factors (inorganic phosphorus level at the initiation of treatment, initial dosage of vitamin $\mathrm{D}$, initial dosage of phosphate) had no significant correlation with FHt.

Stepwise regression revealed that the same two factors were significantly correlated with $\mathrm{FHt}$ : IHt and age at the initiation of treatment $(r=0.70$, $\mathrm{p}=0.02$ ).

The same analyses were done by using (FHt-THt) and (FHt-IHt) with both simple and stepwise regression. These two parameters for improvement of height did not correlate with any of the factors as described.

\section{Discussion}

There was a significant improvement of height of the participants with XLH who were treated with vitamin D and phosphate. FHt for all participants was $-1.69 \pm 1.11 \mathrm{SD}$. IHt for all participants was $-2.38 \pm 0.88 \mathrm{SD}$, which was significantly shorter than FHt. It was reported that the mean of adult heights of untreated patients with XLH was $-2.91 \mathrm{SD}$ [2]. Previous studies showed that FHt $(-2.07 \mathrm{SD})$ was significantly higher than the value before treatment $(-2.79$ SD) [6]. These data suggest

Table 2. Final height

\begin{tabular}{lccc}
\hline & Group $\mathrm{D}_{2}$ & Group $\alpha \mathrm{D}_{3}$ & total \\
\hline \multicolumn{1}{c}{$\mathrm{n}$} & 10 & 12 & 22 \\
Initial height(SD) & $-2.73 \pm 0.78$ & $-2.07 \pm 0.88$ & $-2.38 \pm 0.88$ \\
Final height(SD) & $-2.07 \pm 0.84$ & $-1.38 \pm 1.24$ & $-1.69 \pm 1.11$ \\
FHtSDS-THtSDS & $-1.41 \pm 1.21$ & $-1.19 \pm 1.14$ & $-1.31 \pm 1.10$ \\
\hline
\end{tabular}




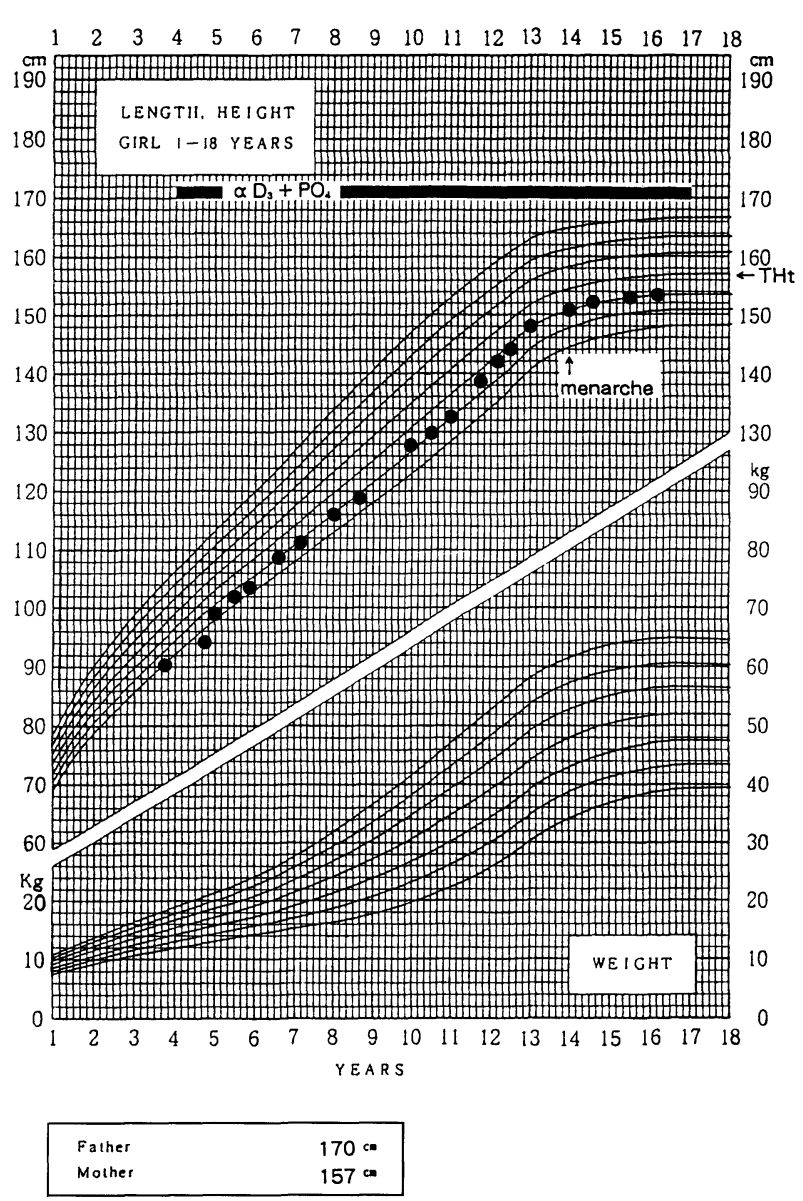

Fig. 1A. Representative growth curve (1). This patient was successfully treated in terms of height.

that vitamin $\mathrm{D}$ and phosphate treatment improves adult height of $\mathrm{XLH}$, which is also true in Japanese population. On the contrary, no beneficial effect of treatment with vitamin $\mathrm{D}$ and phosphate on adult height was reported [2] which may be due to the selection bias of the patients [3].

Treatment did not completely normalize height in our study. FHt was shorter than normal adult height. Osteomalacia was not cured completely based on histological examinations in our two participants examined with bone obtained by osteotomies (data not shown). Previous studies showed the same unsatisfactory effects of therapy on height [10, 11] and on Osteomalacia $[1,12,13]$. One of the reasons for these incomplete effects may be because inorganic phosphorus levels were not normalized consistently.

There was no significant difference between vita$\min \mathrm{D}_{2}$ and $1 \alpha$ hydroxyvitamin $\mathrm{D}_{3}$ therapy concerning

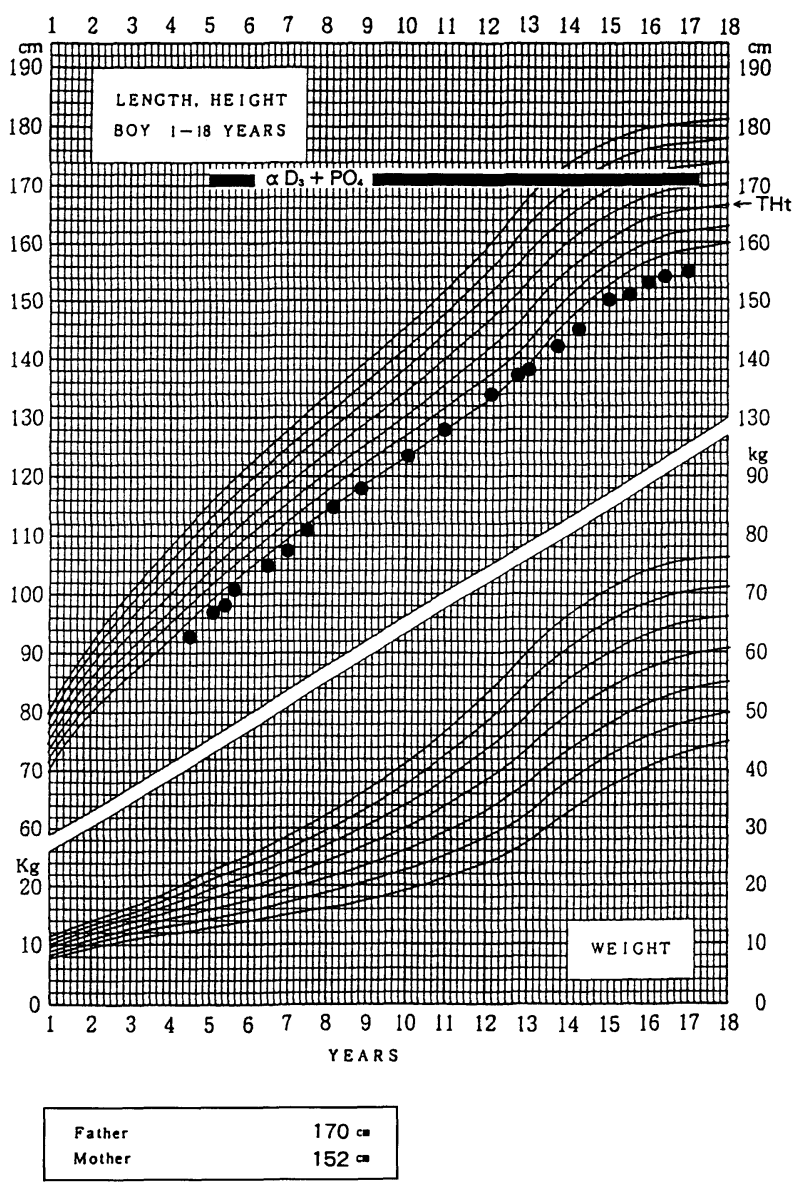

Fig. 1B. Representative growth curve (2). This patient responded poorly in terms of height.

improvement of height, on the contrary to a previous report [14]. One reason for the absence of difference in our study is the small sample size of our treatment groups or wide clinical variations of XLH. It is known that patients with XLH are clinically heterogeneous. Although it is difficult to evaluate the severity of the disease, there were no significant differences of heights, ages and serum inorganic phospharus levels at the initiation of treatment between group $\mathrm{D}_{2}$ and group $\alpha \mathrm{D}_{3}$.

Relative importance of phosphate and vitamin D on growth remains to be analyzed, because all participants took phosphate in this study. One previous report suggests that phosphate did not affect on growth [11]. Another study reported that phosphate supplement accelerated growth, although vitamin D alone did not affect the rate of growth [15].

In conclusion, FHt SDS for 22 Japanese participants with XLH was $-1.69 \pm 1.11$ SD. Combi- 
nation therapy of vitamin D and phosphate partially improves final height of Japanese patients with XLH.

\section{Acknowledgments}

Initial treatment of all the participants were begun by Dr. Yutaka Tsuchiya. We are indebted for his critical comments in the preparation of this manuscript.

\section{References}

1. Glorieux FH, Marie PJ, Pettifor JM, Delvin EE (1980) Bone response to phosphate salts, ergocalciferol, and calcitriol in hypophosphatemic vitamin D-resistant rickets. N Engl J Med 303(18): 1023-1031.

2. Stickler GB, Morgenstern BZ (1989) Hypophosphatemic rickets: final height and clinical symptoms in adults. Lancet 2(8668): 902-905.

3. Stamp T, Goldstein AJ (1990) Hypophosphataemic rickets and final height. Lancet 335(8688): 536-537. letter

4. Yoshikawa S, Ohno A, Amagai H, Ikeda K, (1992) A report on two siblings with vitamin $\mathrm{D}$ resistant rickets treated with1 alpha-hydroxy-vitamin $\mathrm{D}_{3}$ until completion of the growth. Nippon Seikeigeka Gakkai Zasshi 66(11): 1137-1345.

5. Berndt M, Ehrich JH, Lazovic D, Zimmermann J, Hillmann G, Kayser C, Prokop M, Schirg E, Siegert B, Wolff G, Brodehl J (1996) Clinical course of hypophosphatemic rickets in 23 adults. Clin Nephrol 45(1): 33-41.

6. Reusz GS, Hoyer PF, Lucas M, Krohn HP, Ehrich JH, Brodehl J (1990) X linked hypophosphataemia: treatment, height gain, and nephrocalcinosis. Arch Dis Child 65(10): 1125-1128.

7. Koto S (1991) Participation of disturbed vitamin D metabolism in pathogenesis of hypophosphatemic vitamin D-resistant rickets. Nihon shounika gakkai zasshi 95(12): 2592-2599 (in Japanese).

8. Suwa S, Tachibana K, Maesaka H, Yokota S (1992) Longitudinal Standards for height and height velocity for Japanese children from birth to maturity. Clin
Pediatr Endocrinol 1: 5-13.

9. Ogata T, Matsuo N, Tamai S, Osano M, Tanngo T (1990) Target range of Japanese: set up target height and target range. Nihon shounika gakkai zasshi 94: 1535-1540 (in Japanese).

10. Verge CF, Lam A, Simpson JM, Cowell CT, Howard NJ, Silink M (1991) Effects of therapy in X-linked hypophosphatemic rickets. N Engl J Med 325: 18431848.

11. Seikaly MG, Browne RH, Baum M (1994) The effect of phosphate supplementation on linear growth in children with X-linked hypophosphatemia. Pediatrics 94: 478-481.

12. Sullivan W, Carpenter T, Glorieux F, Travers R, Insogna K (1992) A prospective trial of phosphate and 1,25-dihydroxyvitamin $\mathrm{D}_{3}$ therapy in symptomatic adults with X-linked hypophosphatemic rickets. $J$ Clin Endocrinol Metab 75(3): 879-885.

13. Dumas R, Guermoud C, Garabedian M, Meunier JP (1985) Biological and bone histomorphometric studies in hypophosphatemic vitamin-resistant rickets treated with 1,25-(OH)2D and phosphorus. Arch Fr Pediatr 42(7): 507-510.

14. Balsan S, Tieder M (1990) Linear growth in patients with hypophosphatemic vitamin D-resistant rickets: Influence of treatment regimen and parental height. $J$ Pediatr 116: 365-371.

15. McEnery PT, Silverman FN, West CD (1972) Acceleration of growth with combined vitamin D-phosphate therapy of hypophosphatemic resistant rickets. J Pediatr 80(5): 763-774. 